\title{
Cross-Sectional Analysis of Picture Descriptions of Healthy Young and Older Adults
}

\author{
Johémie Boucher ${ }^{1,2}$, B. Sc., Antoine Slegers ${ }^{1,2}$, B. A., B. Sc., \& Simona M. Brambati ${ }^{1,2}$, Ph. D. \\ ${ }^{1}$ Département de psychologie, Université de Montréal \\ ${ }^{2}$ Centre de Recherche de 1'Institut Universitaire de Gériatrie de l'Université de Montréal
}

\begin{abstract}
It is poorly understood whether and how normal aging affects different aspects of connected speech production, such as fluency, informativity, efficiency, and vocabulary use. The present study crosssectionally investigates the effects of age on a broad variety of language production measures, using connected speech samples elicited by the two most frequently used picture description tasks. Twenty-six young (20-25 y.o.) and twenty-two older participants (55-90 y.o.) were included in this study. Speech samples were transcribed using the CLAN program and eight measures were extracted. Our results indicate that, in a picture description task, older adults produce more disruptions to fluency, but that lexical diversity, informativity, and efficiency of speech remain unaffected by age. The use of less frequent words by older adults might reflect a larger vocabulary size. These findings have implications for future studies assessing changes in connected speech production, in both healthy and clinical populations.
\end{abstract}

Keywords: normal aging, language production, connected speech, picture description task, word-finding difficulties

Le vieillissement normal module certaines habiletés cognitives, mais on ne sait pas si, et de quelle manière, différents aspects de la production du discours continu, tels que la fluence, l'informativité, l'efficacité et l'utilisation du vocabulaire, sont affectés. La présente étude transversale examine les effets de l'âge sur plusieurs mesures langagières à partir d'échantillons de discours continu suscités par les deux tâches de description d'image les plus utilisées. Vingt-six jeunes (20-25 ans) et vingt-deux participants âgés (55-90 ans) ont été recrutés. Les échantillons ont été transcrits via le programme CLAN et huit mesures ont été extraites. Nos résultats indiquent que les adultes plus âgés produisent plus de bris de fluidité verbale, mais que la diversité lexicale, l'informativité et l'efficacité du langage ne sont pas affectées par l'âge. L'usage de mots moins fréquents par les adultes plus âgés pourrait refléter un vocabulaire plus étendu. Ces résultats ont des implications pour les études futures portant sur les changements dans la production de discours continu chez les populations saines et cliniques.

Mots clés : vieillissement normal, production langagière, discours continu, tâche de description d'images, manque du mot

While the literature has consistently shown that an evolution of language production abilities is expected to occur across the adult lifespan, the extent to which normal aging may affect language production remains unclear. Indeed, the available evidence provides mixed results: some studies show that aspects of language function remain relatively stable or improve over time (Cooper, 1990; Salthouse, 2003; Verhaegen, 2003) while others show a significant decline in language production with normal aging (Burke, MacKay, \& James, 2000; Verhaegen \& Poncelet, 2012). A better understanding of the evolution of language production abilities throughout normal aging is a fundamental step to identify changes that could be associated with pathological aging (Shewan \&

Correspondence concerning this article should be addressed to/ $\mathrm{La}$ correspondance concernant cet article doit être adressée à :

Simona Brambati, Département de psychologie, Université de Montréal

E-mail/courriel: simona.maria.brambati@umontreal.ca
Henderson, 1988). However, more research is needed in that field.

Previous studies have attempted to measure agerelated changes in language abilities by comparing the performance of young and older adults without cognitive impairment in various standardized tasks involving single-word processing. Common procedures include verbal fluency (Brickman et al., 2005; Clark et al., 2009), a timed task which requires participants to produce words that either begin with a certain letter of the alphabet or are exemplars of a particular category (e.g., animals, vegetables), and picture naming tests (Verhaegen \& Poncelet, 2012), where the participants are asked to name various pictures correctly. Some authors also use vocabulary tests which, as opposed to naming and fluency tasks, do not rely on explicit word retrieval. In this type of task, participants are asked to supply dictionary-like definitions for various words (Verhaeghen, 2003). In 
general, single-word processing studies have reported a preservation of abilities in language tasks that do not imply explicit word retrieval (Kavé \& Yafé, 2014; Verhaegen, 2003), but a significant decline of performance with advancing age in language production tasks involving naming and fluency (Brickman et al., 2005; Connor, Spiro, Obler, \& Albert, 2004; Heine, Ober, \& Shenaut, 1999; Tombaugh, Kozak, \& Rees, 1999; Verhaegen \& Poncelet, 2012). Thus, evidence from single-word processing task suggests that unlike knowledge of word meaning, which is preserved or even improved with aging (Chapleau et al., 2017; Verhaegen, 2003), the ability to retrieve words typically declines with age (Burke \& Shafto, 2004). In fact, word-finding difficulties (WFD; i.e., difficulties in retrieving words in the mental lexicon; Hughes, 2009) are one of the most frequent concerns expressed by healthy older adults, with as many as two-thirds reporting difficulties with word retrieval (Condret-Santi et al., 2013). In literature on aging, the most common explanation for WFD in older adults is Burke, MacKay, Worthley, and Wade's (1991) hypothesis of a "transmission defect" associated with normal aging (Le Dorze \& Bédard, 1998; Spieler \& Griffin, 2006; Thornton \& Light, 2006). According to this hypothesis, aging weakens the connection between a word's semantic (i.e., meaning of a word) and phonological (i.e., sound or appearance of a word) forms, causing word production failures.

However, whereas single-word processing tasks are widely used and can provide information about age-related changes affecting language production, they do not allow the understanding of the impact of healthy aging on speech production in a context more representative of everyday communication. In addition, the ecological validity of single-word tests is subject to debate (Kavé, Samuel-Enoch, \& Adiv, 2009; Sajjadi, Patterson, Tomek, \& Nestor, 2012).

Growing consensus indicates that the analysis of connected speech samples allows to draw a global approximation of language production abilities and may offer a more ecologically valid approach to understanding the effects of age-related changes in speech production. Connected speech refers to the "term used in linguistics to refer to spoken language when analyzed as a continuous sequence, as in normal utterances and conversations" (Hughes, 2009). Several tasks can be used to elicit connected speech samples. These include: structured or semi-structured interviews (Glosser \& Deser, 1992; Kemper, Kynette, Rash, O'Brien, \& Sprott, 2008; Mackenzie, 2000), in which participants are asked to answer open-ended questions or to describe important events, people, etc.; story-telling procedures (Conroy, Sage, \& Ralph, 2011; Fraser et al., 2014; Wright, Capilouto,
Srinivasan, \& Fergadiotis, 2011), where connected speech samples are elicited by asking the participant to tell a specific story; and picture description tasks (Brookshire \& Nicholas, 1994b; Capilouto, Wright, \& McComas Maddy, 2016; Kavé et al., 2009; Le Dorze \& Bédard, 1998). The latter consists in the detailed description of a standardized pictorial stimulus representing an everyday-life scene. As opposed to the other aforementioned speech-eliciting methods, picture description tasks present the advantage of providing a relatively constrained discourse sample with expected topics (Chenery \& Murdoch, 1994). This allows a standardized approach to study language production in a specific context while facilitating speech comparison across groups. Moreover, picture description tasks are quick and easy to administer and can provide information about multiple aspects of speech production. This procedure is the most frequently used to study connected speach in various populations, including healthy older adults (e.g., Kavé et al., 2009; Le Dorze \& Bédard, 1998; Mortensen, Meyer, \& Humphreys, 2006), patients with Alzheimer's disease (AD; Slegers, Filiou, Montembeault, \& Brambati, 2018) or at risk for developing AD (Ahmed, Haigh, de Jager, \& Garrard, 2013), and individuals with aphasia (Gordon, 2008; Vandenborre, Visch-Brink, van Dun, Verhoeven, \& Mariën, 2018).

Disruptions to fluency, lexical measures, informativity, and efficiency are aspects of speech production that are suspected to be influenced by age and have thereby been frequently studied in the connected speech literature (e.g., Kavé \& Goral, 2016a; Le Dorze \& Bédard, 1998). While available literature relying on picture description tasks suggests certain trends regarding the effects of age on these various aspects of speech production, findings have not systematically been replicated across studies. The following paragraphs attempt to summarize the findings regarding the four most frequently analyzed aspects of speech production in studies using picturedescription tasks.

\section{Disruptions to fluency}

Disruptions to fluency refer to interruptions in the normal course of speech production. Most studies relying on connected speech elicited by picture description tasks showed an increase in disruptions to fluency with normal aging, indicated among others by a significant increase in word repetitions (Le Dorze \& Bédard, 1998) and "retracings" (i.e., self-corrections or reformulations; Schmitter-Edgecombe, Vesneski, \& Jones, 2000). This effect was mainly attributed to an increase in WFD in healthy older adults (Burke et al., 1991). In the connected speech literature, disruptions to fluency are considered evidence for word-finding 
failures as they could indicate that individuals are searching for words during speech production (Kavé \& Goral, 2016a). Le Dorze and Bédard (1998) suggested that an increase in the number of repetitions in older adults' speech is compatible with the transmission defect hypothesis (Burke et al., 1991). Due to a weakened connection between the words' semantic and phonological forms, older adults may have more difficulty in retrieving new words and may more readily access words that have been recently activated, hence their re-use.

\section{Lexical measures}

Lexical aspects of speech refer to the vocabulary used in the task and include both lexical diversity (i.e., the range of vocabulary deployed by a speaker; Fergadiotis, Wright, \& Capilouto, 2011) and lexical frequency (i.e., the mean frequency, according to published norms, of the words selected for production) measures. These measures could both provide an estimation of vocabulary size (Kavé \& Goral, 2016a). When it comes to these aspects of speech, it currently remains unclear how age affects the performance of healthy older adults.

Lexical diversity. Across studies, lexical diversity is generally estimated by comparing the number of different words used by the participants (types) to the total number of words produced (tokens). The most common measures of lexical diversity are the Typetoken ratio (TTR) and the Voc- $D$ (i.e., TTR adjusted for speech sample size). Some studies propose that aging may result in an impoverished lexical diversity in a picture description task (Capilouto et al., 2016): as lexical diversity reflects the frequency with which the participant retrieves unique labels, it could decline as a result of repetitiveness in older adults' speech (Kavé et al., 2009). However, Fergadiotis, Wright, and Capilouto (2011) found that older adults did not use a restricted lexicon, which suggests that lexical diversity measures do not capture age-related changes in language production abilities.

Lexical frequency. Some evidence from single word production tasks supports the hypothesis that older adults have more difficulties in retrieving low frequency words (Burke \& Shafto, 2004), for which, due to less frequent use, the connections between the semantic and phonological forms are weaker and harder to activate. Kavé et al. (2009) and Dennis and Hess (2016) instead found that connected speech samples of older adults were characterized by a lower mean word frequency (that is, they used less frequent words than younger adults). After ruling out the possibility that age-related changes in lexical frequency could result from a generational difference in the common lexicon, Kavé et al. (2009) hypothesized that older adults have a larger vocabulary size: they might benefit from a richer lexicon, containing more low-frequency words, some of which haven't been learned by younger speakers yet.

\section{Informativity and efficiency}

Most of the research focusing on informativity (i.e., the meaning and quantity of information transmitted) and efficiency of speech (i.e., the rate at which relevant information is transmitted) indicates a preservation of informativity with age, but a decline in efficiency.

Informativity. Informativity can be measured by evaluating the number of thematic (Marini, Boewe, Caltagirone, \& Carlomagno, 2005) or content units (Le Dorze \& Bédard, 1998; Mackenzie, 2000) produced by a participant. With regards to this measure, while results are not entirely consistent (Marini et al. 2005), it is generally agreed upon that healthy aging is not accompanied by a decline in the ability to convey relevant information (Le Dorze \& Bédard, 1998; Mackenzie, Brady, Norrie, \& Poedjianto, 2007). On the contrary, a deterioration of the ability to convey relevant information was associated with neurodegenerative diseases or language-specific impairments (Shewan \& Henderson, 1988).

Efficiency. As for the efficiency of speech, available literature generally points to a decline with normal aging, older adults usually taking more time and/or more words to convey the same amount of information (Capilouto et al., 2016; Le Dorze \& Bédard, 1998). This being said, literature remains unclear as to whether this could be caused by an increase in WFD (Le Dorze \& Bédard, 1998), or by general processes that are not language-specific, such as an age-related decline in the ability to inhibit irrelevant information, resulting in an increase in offtopic speech (Arbuckle, Nohara-LeClair, \& Pushkar, 2000) and a decrease in efficiency.

This summary of available data suggests that, up until now, studies analyzing connected speech elicited by picture description tasks have not provided a general and consistent approximation of the way language production evolves during normal aging. Previous studies usually focused on a restricted set of variables, which varied greatly from a study to another, but did not draw a complete estimation of the way healthy aging may affect the different aspects of speech production. Additionally, different picture stimuli have been used in connected speech literature. While the most commonly used picture stimulus is the Cookie Theft Picture from the Boston Diagnostic Aphasia Examination (Goodglass \& Kaplan, 1972), 
some authors have chosen to rely on other stimuli, such as the Picnic Scene (Western Aphasia Battery; Risser \& Spreen, 1985) or, less often, the Bank Robbery Picture (Montreal-Toulouse 86 Battery; Joanette, Nespoulous, \& Roch Lecours, 1998). However, it is unclear how the characteristics of the stimulus may affect language production in healthy older adults.

Moreover, despite the numerous advantages associated with picture description tasks, it has been suggested that connected speech samples elicited by a single picture stimulus might not be long enough to allow a representative evaluation of one's language production abilities. While in a picture description task, sample length is restricted by the constraints of the task (Sajjadi et al., 2012), most studies focusing on age-related changes in language production used connected speech samples elicited by only one stimulus (Capilouto, Wright, \& Wagovich, 2005). Work from aphasia literature showed that sample length influences the stability of speech measures, hence Brookshire and Nicholas' (1994a, 1994b) suggestion that connected speech samples between 300 and 400 words obtained by combining different stimuli should be used for a language evaluation. While guidelines regarding the amount of data that should be made available to allow a representative approximation of the language performance of healthy older adults with picture description tasks remains unclear, recommendations from previous literature suggest that using only one picture description might not be enough.

Thus, this study investigated the impact of age on connected speech production while broadening the variety of variables studied within a single sample and combining speech elicited by two picture description tasks in order to obtain more data to analyze. Our main objective was to cross-sectionally investigate the effects of age on connected speech variables relating to lexical, disruptions to fluency, informativity, and efficiency measures extracted from connected speech samples elicited by the two most commonly used picture description tasks (i.e., the Picnic Scene and the Cookie Theft Picture).

A secondary and exploratory objective was to assess if the results regarding the effects of age on speech production obtained using each picture stimulus are comparable to the ones obtained by combining the connected speech samples elicited by both picture description tasks. To our knowledge, no previous study has compared the effects of the two most commonly used picture description tasks on measures of discourse production in healthy older adults.
We hypothesize that:

1. Older adults will produce more disruptions to fluency (i.e., repetitions and retracings) than young adults.

2. The lexical diversity of young and older adults' speech will not differ, but older adults will produce less frequent words than the younger group.

3. Older participants will convey as much relevant information as the younger group.

4. Older participants will be less efficient than young adults: they will take more words and more time to convey relevant information.

\section{Materials and methods}

\section{Participants}

Twenty-six young participants (20-25 y.o.) and thirty older participants (50-90 y.o.) were recruited through the participants' bank of the Centre de recherche de l'Institut Universitaire de Gériatrie de Montréal. They were all Canadians, and their first language was French. Exclusion criteria included language or neurological impairments and uncorrected visual or auditive deficits. Seven participants from the older group were excluded due to a Montreal Cognitive Assessment (MoCA; Nasreddine et al., 2005) score below 26/30, which is the proposed cutoff for possible neurocognitive impairment. An additional older participant presenting extreme scores ( $\geq 3.29 S D$ from the mean) for several language measures was excluded from our sample.

\section{Procedure}

The experiment took place at the Centre de recherche de l'Institut Universitaire de Gériatrie de Montréal in one uninterrupted session which lasted up to an hour. After signing the consent form and completing a health and sociodemographic questionnaire, all participants underwent the same protocol. They first completed the MoCA, a brief screening tool for mild cognitive impairment targeting short term memory, visuospatial abilities, executive functions, attention, concentration, working memory, orientation to time and place, and language. As a complement to the picture description tasks, participants then had to complete the Pyramids and Palm Trees Test (PPTT; Howard \& Patterson, 1992), a 52-items test assessing the degree to which a subject can access meaning from pictures and words, and the French-Canadian abbreviated version of the Boston Naming Test (BNT-30; Colombo \& Assal, 1992), a 30 -items picture naming test on which young adults generally outperform older adults (Slegers et al., 2018). Then, the Similarities, a verbal subtest of the 
Wechsler Adult Intelligence Scale (WAIS-IV; Wechsler, 2008) where the participant is asked to describe the relationship between two words, as well as the Trail Making Tests $A$ and $B$ (TMT: Army Individual Test Battery, 1944), a visual-motor sequencing task evaluating motor speed and flexibility, were administered. Finally, the participants completed the two most commonly used picture description tasks, with their order of presentation randomized across participants: The Picnic Scene from the Western Aphasia Battery and the Cookie theft Picture from the Boston Diagnostic Aphasia Examination. For each task, connected speech samples were recorded using a Sony IC recorder icd-px312.

\section{Transcription}

Recordings were transcribed by the investigator and a research assistant using the Computerized Language Analysis (CLAN; MacWhinney \& Wagner, 2010) program, following the CHAT format guidelines (MacWhinney, 2000). The investigator annotated hesitations, repetitions, commentaries on the task, and examiner's interventions.

\section{Connected speech measures}

\section{Disruptions to fluency.}

Repetition. A repetition is counted by the CLAN program every time a word is inappropriately uttered more than one time (e.g., "c'est le le le ballon"/"it is the the the ball"). For each participant, repetition scores from the two tasks were summed.

Retracing. A retracing is counted by the CLAN program every time a modification is made to one or more previous words, for example: "elle a bloqué bouché [le renvoi d'eau]"/"she blocked clogged [the backwater]". For each participant, retracing scores from the two tasks were summed.

\section{Lexical measures.}

\section{Lexical diversity.}

Type/token ratio (TTR). Lexical diversity measure automatically calculated by the CLAN program by dividing the number of different words used by the participants (types) by the total number of words produced (tokens), excluding repetitions and retracings (Types/Tokens). For each participant, TTR scores for the two tasks were averaged. This measure is the most frequently used to evaluate the lexical diversity of speech samples.

$D$. Lexical diversity measure estimated using the Voc- $D$ program in CLAN. It provides a measure of lexical diversity that is considered more robust to differences in sample length than the TTR (Capilouto et al., 2016). Essentially, this measure is calculated by comparing randomly sampled data from the transcript to a mathematical model representing how TTR varies with token size (cf. McKee, Malvern, \& Richards, 2000 for a detailed explanation of how $D$ is calculated from a transcript). For each participant, $D$ scores for the two tasks were averaged.

Lexical frequency. Frequency of each word type (i.e., all the different words used by a given participant) are retrieved from Lexique 3.82 (New, Pallier, Ferrand, \& Matos, 2001). This database contains the lexical frequencies of 135000 French words extracted from a 15-million-words corpus (Frantext; https://www.frantext.fr/). A mean of word frequencies was computed. For each speech sample, we used the procedure described by Kavé et al. (2009): we computed the mean frequency by first adding up the lexical frequencies of all types and then dividing it by the total number of types produced by that person. This allowed to control for the length of the picture description, ensuring that the frequency score was not affected by the number of words produced. For each participant, the lexical frequency means for the two tasks were averaged.

\section{Informativity.}

Information content units (ICUs). Prespecified unit of truthful and relevant information conveyed by the speaker (Cooper, 1990). Both connected speech samples were scored for ICU by two independent examiners, using a list of predefined ICUs, separated in places (e.g., in a kitchen), people (e.g., the mother), objects (e.g., a kite), and actions (e.g., pouring [a drink]). The mean inter-rater agreement for both picture stimuli reached $99 \%$. For the Cookie Theft Picture, we used a list of 24 ICUs defined by Croisile et al. (1996), and for the Picnic Scene, we used a list of 30 ICUs adapted from Jensen, Chenery, and Copland (2006). Scores on both lists were summed, so that each participant could obtain a maximal score of 54 ICUs.

\section{Efficiency.}

Efficiency 1. Number of words needed for the participant to convey one ICU (Number of words produced/number of ICUs). For each participant, mean efficiency 1 was calculated by averaging efficiency scores obtained on both tasks.

Efficiency 2. Number of seconds needed for the participant to convey one ICU (Number of seconds of the connected speech sample/number of ICUs). For each participant, mean efficiency 2 was calculated by averaging efficiency scores obtained on both tasks. 


\section{Results}

We expected older adults to produce more disruptions to fluency and less frequent words than the younger group, but that lexical diversity would not differ between the two groups. We also hypothesized that older participants would convey as much information as the younger group but would take more words and time to do so. We conducted independent samples $t$-tests to compare the young and older adults for sociodemographic characteristics, scores on the neuropsychological assessment tasks, and all of the connected speech measures. We then tested for possible interactions between age (i.e., young and older adults) and picture stimulus (i.e., Picnic Scene or Cookie Theft Picture) for all the connected speech measures using mixed design ANOVAs. For the duration of the connected speech samples, nonparametric Mann-Whitney $U$ tests were used for group comparison. To minimize their impact on mean estimation without reducing sample size, extreme scores presented by a participant were reduced at $+3,29 S D$ from the mean score (Field, 2013).

\section{General results}

Sociodemographic characteristics of the sample are presented in Table 1. While both groups contained more females than males (younger group: 19/7; older group: 16/6), the female/male ratio did not significantly differ from one group to another $(t=0.03, p=.979)$. Moreover, for most speech measures, available literature relying on picture description tasks does not mention any significant gender effect (Mackenzie, 2000; Mackenzie et al., 2007). No group differences were observed for education level $(t=-0.30, p=.762)$. Descriptions for the Cookie Theft Picture were on average 166.15 words long, and descriptions for the Picnic Scene were significantly longer $(t=-4.94, p<.001)$, containing on average 222.27 words. No significant difference $(t=-0.56, p=.578)$ was detected between the younger and the older group regarding the number of words produced for the combined samples. Both groups produced connected speech samples of equal

Table 1

Sociodemographic characteristics of sample

\begin{tabular}{lcc}
\hline & $\begin{array}{c}\text { Young group } \\
(n=26)\end{array}$ & $\begin{array}{c}\text { Older group } \\
(n=22)\end{array}$ \\
\hline Female/male ratio & $19 / 7$ & $16 / 6$ \\
$\begin{array}{l}\text { Age } \\
M(S D)\end{array}$ & $22.27(1.99)$ & $73.32(9.86)$ \\
$\begin{array}{l}\text { Education (years) } \\
M(S D)\end{array}$ & $15.62(1.75)$ & $16.00(6.17)$ \\
\hline
\end{tabular}

duration $(U=221, p=.179)$, and comparable words per minute $(t=-0.85, p=.398)$. No interaction was found between age and picture stimulus for any of those measures $(p=.325 ; .183 ; .881)$.

\section{Neuropsychological assessment}

Group comparison revealed no significant difference for the performance on the $\operatorname{MoCA}(t=0.23$, $p=.814$,$) , the BNT-30 (t=-0.94, p=.351)$, and the Similarities $(t=1.51, p=.138)$. Older adults performed slightly better on the PPTT $(t=-3.15$, $p=.003)$ and took significantly more time to complete both versions of the TMT (A: $t=-6.23, p<.001$; $\mathrm{B}: t=-5.29, p<.001)$. Results from the neuropsychological and language assessments are summarized in Table 2.

\section{Connected speech measures}

Disruptions to fluency. Group comparisons of the combined connected speech samples showed that the older group produced on average more disruptions to fluency compared to the younger group. When considering data for both picture stimuli, the older group produced more repetitions $(t=-3.36, p=.002$, $d=4.43)$ and retracings $(t=-3.92, p<.001, d=3.99$; cf. Table 3 for mean scores). No significant age by picture stimulus interaction was found for any of these measures $\left(p_{\mathrm{s}}=.290 ; .279\right)$.

\section{Lexical measures.}

Lexical diversity. An independent samples $t$-test conducted on the combined connected speech samples showed no significant differences between the younger and the older group, for both lexical diversity measures investigated. Means TTR $(t=0.67, p=.506)$ and $D(t=0.54, p=.590)$ were similar for both groups. No age by picture stimulus interactions were found $\left(p_{\mathrm{s}}=.457 ; .379\right)$.

Lexical frequency. Group comparison conducted on combined connected speech samples revealed a significant effect of age on lexical frequency $(t=2.49$, $p=.017, d=0.11)$, with the older group producing more low-frequency words than the younger group. A significant age by picture stimulus interaction was found $(p=.019)$. Analysis of simple effects showed that the older group produced significantly more lowfrequency words during the description of the Cookie Theft Picture $(t=3.01, p=.002)$, but did not show any significant differences between the two groups' mean lexical frequency on the Picnic Scene $(t=1.24$, $p=.145)$.

Informativity. Analysis conducted on combined results for both picture description tasks showed that the older group conveyed as many ICUs as the younger group $(t=-0.28, p=.783)$. No age by picture 
Table 2

Neuropsychological and language assessment

\begin{tabular}{lccccc}
\hline \multicolumn{2}{c}{ Younger participants } & \multicolumn{2}{c}{ Older participants } \\
\hline & $\underline{M}$ & $\underline{S D}$ & $\underline{M}$ & $\underline{S D}$ & $\underline{p}$ \\
MoCA & 28.31 & 1.12 & 28.23 & 1.23 & $* *$ \\
PPTT & 48.69 & 1.85 & 50.18 & 1.33 & \\
BNT & 29.61 & 0.64 & 29.55 & 0.60 & \\
Similitudes & 29.00 & 2.93 & 27.45 & 4.14 & $* *$ \\
TMT-A (seconds) & 22.15 & 7.13 & 37.14 & 9.52 & $* *$ \\
TMT-B (seconds) & 49.69 & 18.33 & 83.11 & 26.16 & $*$
\end{tabular}

Note. ${ }^{* *}=p<.01 ; \mathrm{MoCA}=$ Montreal Cognitive Assessment score; $\mathrm{PPTT}=$ Pyramids and Palm Trees Test score;

$\mathrm{BNT}=$ Boston Naming Test score; TMT-A = Trail-Making Test, version A; TMT-B = Trail-Making Test, version B.

Table 3

Participants' scores for the combined picture description tasks

\begin{tabular}{|c|c|c|c|c|c|}
\hline & \multicolumn{2}{|c|}{ Younger participants } & \multicolumn{2}{|c|}{ Older participants } & \multirow[b]{2}{*}{$\underline{p}$} \\
\hline & $\underline{M}$ & $\underline{S D}$ & $\underline{M}$ & $\underline{S D}$ & \\
\hline \multicolumn{6}{|l|}{ General } \\
\hline Total number of words & 351.12 & 177.98 & 379.71 & 170.80 & \\
\hline Total duration & 146.77 & 79.06 & 166.95 & 83.89 & \\
\hline Meanwords per minute & 146.03 & 23.46 & 140.49 & 33.61 & \\
\hline \multicolumn{6}{|l|}{ Disruptions to fluency } \\
\hline Total number of repetitions & 4.19 & 3.98 & 8.50 & 4.91 & ** \\
\hline Total number of retracings & 4.15 & 3.86 & 8.68 & 4.13 & ** \\
\hline \multicolumn{6}{|l|}{ Lexical } \\
\hline Mean lexical frequency & 2.26 & 0.12 & 2.17 & 0.09 & $*$ \\
\hline Mean TTR & 0.52 & 0.08 & 0.51 & 0.07 & \\
\hline Mean $D$ & 71.28 & 14.92 & 68.93 & 14.93 & \\
\hline \multicolumn{6}{|l|}{ Semantic } \\
\hline Total number of ICUs & 39.61 & 6.98 & 40.14 & 6.07 & \\
\hline \multicolumn{6}{|l|}{ Pragmatic } \\
\hline Mean efficiency 1 & 8.79 & 3.03 & 9.29 & 3.54 & \\
\hline Mean efficiency 2 & 3.68 & 1.41 & 4.19 & 1.84 & \\
\hline
\end{tabular}

Note ${ }^{*}=p<.05 ; * *=p<.01 ;$ TTR $=$ type-token ratio; ICUs $=$ information content units; Efficiency $1=$ number of words produced / total number of ICUs; Efficiency 2 = number of seconds of the samples / total number of ICUs.

stimulus interaction was found for the amount of relevant information conveyed $(p=.486)$.

Efficiency. ICUs/duration $(t=-1.08, p=.286)$ and ICUs/words did not differ significantly $(t=-0.52$, $p=.606$ ) between the two groups. No significant age by picture stimulus interaction were found for neither of the efficiency measures $\left(p_{\mathrm{s}}=.331 ; .431\right)$.

\section{Discussion}

The present study allowed for the investigation of multiple aspects of speech production within a single sample by analyzing connected speech elicited by two picture description tasks. Our results indicate that connected speech samples of older adults are characterized by a higher rate of disruptions to fluency and more low-frequency words. However, lexical diversity, informativity, and efficiency of speech are not significantly affected by age.

Older and younger adults' performances were comparable for all standardized assessment tasks (i.e., MoCA, BNT-30, and Similarities), except for the TMTs A and B and the PPTT. As a result of general age-related perceptual and motor speed differences, poorer performance of older adults on the TMTs was expected (Salthouse et al., 2000). Older adults performed only slightly better on the PPTT, which is 
consistent with the assumption that no degradation of semantic knowledge occurs throughout healthy aging (Nilsson, 2003).

Interestingly, while previous literature had suggested that healthy aging could affect picture naming abilities, the difference between the younger and the older group for scores on the BNT-30 did not reach significance. Thus, while the observed increase in disruptions to fluency suggests an effect of age on speech production in context, older adults did not perform significantly worse than the younger adults on this picture naming task. To explain these unexpected results, we can hypothesize that picture description tasks may be more sensitive tools than standardized, single-picture naming tasks such as the BNT-30 for assessing changes occurring in healthy individuals over the course of aging. Nevertheless, these results should be interpreted with care.

First, while naming accuracy is known to be influenced by education level, our sample was composed of highly educated older adults. This may have led to underestimating the effects of healthy aging on participants' performance on our naming task. Additionally, the BNT-30, a 30-items single-picture naming task, may have been too easy a task for our healthy and highly educated older adults to reveal significant retrieval failures. In fact, it was shown that other naming tasks including more "difficult" items such as semantically unique entities (e.g., proper nouns designating famous people and places) could be associated with more WFD, in healthy as well as clinical populations (Brédart, 1993; Montembeault et al., 2017). Finally, while WFD may also result in slower naming latencies in healthy older adults, response time was not considered for the BNT30 score in this study.

This study's design did not allow to investigate the stability of the connected speech measures elicited by the picture description tasks. However, the amount of available data obtained by combining the two most commonly used picture description tasks was sufficient (cf. Table 3) according to the most cited guidelines of Brookshire and Nicholas' (1994a, 1994b) in connected speech studies (Bryant, Ferguson, \& Spencer, 2016; Larfeuil \& Le Dorze, 1997; Mayer $\&$ Murray, 2003). This strengthens our confidence in this study's results, considering that the available literature based on connected speech samples elicited by a single picture stimulus did not provide a consistent approximation of language production abilities in healthy older adults.

Our results suggest that older adults' speech is characterized by more disruptions to fluency, as they produce a significantly higher rate of both repetitions and retracings. The relationship between disruptions to fluency and age has been largely documented (Kavé \& Goral, 2016a). While, as previously stated, previous literature is not entirely consistent, our findings replicate the trend indicated by most studies: a majority of authors who used picture description tasks also found an increase of disruptions to fluency in older adults' speech, as measured by more repetitions and/or retracings (Kemper \& Sumner, 2001; Le Dorze \& Bédard, 1998). A higher rate of disruptions to fluency with age was also reported in studies using speech eliciting procedures other than picture description. Among others, Schmitter-Edgecombe et al. (2000) found that older adults produced more repetitions in story narratives, and Bortfeld, Leon, Bloom, Schober, and Brennan (2001) showed that older adults' conversational speech samples were characterized by a slightly higher rate of disruptions to fluency, which included both repetitions and retracings. Thus, our results provide support to the hypothesis that age-related WFD may result in a higher rate of disruptions in older adult's speech. Older adults' tendency to repeat the same words is also consistent with the hypothesis of WFD originating from a "transmission defect" (Burke et al., 1991), according to which aging weakens the connection from lexical to phonological nodes, making word retrieval harder for older adults. Older adults, having more difficulty in retrieving new words, tend to re-use words that have been recently used as their activation requires less effort, hence the repetitions.

As hypothesized and in agreement with most previous literature, analysis of lexical measures typically investigated (i.e., lexical frequency and lexical diversity) did not show that older adults used a restricted lexicon in picture description tasks. Our results rather suggest that while older adults' speech is characterized by a higher rate of disruptions to fluency, their performance on lexical diversity and frequency measures does not decline with age. In fact, Kavé and Goral's review (2016a) suggested that older adults do not use a more restricted set of words in connected speech production. This indicates that the typically investigated lexical measures may not be informative of the extent to which older adults could experience WFD. This being said, even though performance on lexical measures frequently investigated in the scientific literature should not be expected to decrease over the course of healthy aging, these measures could still provide information about other factors affecting language production, such as one's vocabulary size.

Regarding lexical diversity measures, no significant difference was observed between the two groups for the combined picture descriptions. Thus, this measure did not reflect an increase in vocabulary 
size for the older group, both TTR and $D$ scores being statistically equivalent between the two groups. Previous connected speech studies relying on picture description tasks and investigating the effects of age on lexical diversity had yielded highly inconsistent results. While our findings replicate those from Kavé et al. (2009), who used the TTR measure and found no age-related differences for lexical diversity, Capilouto et al. (2016), using the $D$-measure, found a reduced lexical diversity in older adults' speech. As for studies investigating lexical diversity in speech samples elicited by tasks other than picture descriptions, Fergadiotis, Wright, and Capilouto (2011) and Kemper and Sumner (2001) found age-related differences in TTR favoring the older group in conversational speech.

In Fergadiotis et al. (2011), these differences were eliminated when language samples were elicited with pictorial stimuli. Conversely, while Capilouto et al. (2016) had found lower $D$ scores for older participants using a single picture stimulus, group effect was no longer significant when analyzing connected speech samples elicited by a sequential picture task. Thereby, the available literature indicates that the most typical lexical diversity measures do not yield consistent results in picture description tasks and that they do not remain stable across different connected speech eliciting methods. These inconsistencies suggest that lexical diversity measures might present limitations when it comes to estimating vocabulary size, which is compatible with existing criticism. For instance, TTR and other derived measures have been shown to be sensitive to sample length (i.e., shorter samples produce a higher TTRs and longer texts usually have lower TTRs; Fergadiotis et al., 2011; Jarvis, 2002). While $D$ is considered more robust than earlier measures (Owen Van Horne \& Leonard, 2002), Fergadiotis, Wright, and Green (2015) suggested that it may also be sensitive to other factors, such as the number of themes introduced by the participant.

As for the lexical frequency measure, the use of more low-frequency words by older adults in our sample provides support to the hypothesis that a positive age-related change regarding language production is the vocabulary size increase throughout the adult lifespan (Kavé \& Goral, 2016a; Kemper \& Sumner, 2001). Furthermore, our findings are consistent with evidence from previous literature relying on single-word processing tasks, showing that healthy older participants may even outperform younger participants on tasks that do not involve word retrieval and focus on vocabulary knowledge (Kavé \& Yafé, 2014). Interestingly, the significant age by picture stimulus interaction suggests that the lexical frequency measure is sensitive to characteristics of the picture stimulus used to elicit connected speech.
Analysis of simple effects showed that connected speech samples elicited by the Cookie Theft Picture, but not the Picnic Scene, led to differences in mean word frequency between the two groups. As the Cookie Theft Picture elicits a shorter sample but yields results more representative of the combined results, these findings cannot be explained simply by the length of the connected speech sample. We suggest that they could be attributed to the characteristics of the picture stimulus. The Picnic Scene task might place more constraints on the participant's speech, as our results show that this stimulus tends to elicit more low frequency words for both groups.

In contrast, the Cookie Theft Picture is described with words that are, on average, more frequent (cf. Table 3). This stimulus could elicit less constrained connected speech and procure more opportunities for variation in vocabulary use, which increases the probability of finding significant differences between younger and older adults. Thereby, we recommend that the choice of picture stimulus is considered if vocabulary breadth is a variable of interest. Globally, these results indicate that the performance of healthy older adults on lexical measures of speech production should not be expected to decline as a result of age.

Regarding informativity of speech, no significant difference was found between the older and the younger participants for the number of ICUs, with older adults conveying as much relevant information as the younger group. This confirms the trend observed in most studies using ICU extraction (Cooper, 1990) or other methods (Le Dorze \& Bédard, 1998; Mackenzie et al., 2007), suggesting that age does not affect healthy older adults' ability to convey relevant information. As for studies using connected speech eliciting methods that do not involve picture description, they also usually showed that older adults' speech was as informative as the younger group's (Light \& Anderson, 1983; Shewan \& Henderson, 1988). Thus, consensus generally indicates that a decline of speech's informativity is not associated with the evolution of language production in healthy aging. On the contrary, Shewan and Henderson (1988) associated poorer semantic content to neurodegenerative diseases or language-specific impairments associated with pathological aging.

As for the efficiency of discourse, older participants were not significantly less efficient than the younger group in their picture descriptions, though a tendency was observed. While our findings replicate Cooper's (1990), they are not in agreement with most studies using picture description tasks, which converge towards a slight but significant reduction of efficiency in older adults' speech (Capilouto et al., 2016; Capilouto et al., 2005; Kemper, Thompson, \& 
Marquis, 2001; Le Dorze \& Bédard, 1998). As for speech eliciting tasks that do not involve picture descriptions, Arbuckle et al. (2000), Bortfeld et al. (2001), and Mackenzie (2000) found that older adults are significantly less efficient in conversational speech, and James, Burke, Austin, and Hulme (1998) suggested that older adults produce more irrelevant speech in conversational speech, and are thereby less efficient when talking about a personal topic. However, James et al. (1998) found that when presented with a picture stimulus, older adults are as efficient as young adults, in agreement with our results.

While previous literature was unclear as to what caused this reduction in efficiency in healthy older adults, Arbuckle et al. (2000) suggested that the decline in efficiency is explained by a general decline in the ability to inhibit irrelevant information, which results in an increase of off-topic speech with advancing age. This explanation is particularly interesting in that it accounts for inconsistencies between different speech eliciting tasks regarding efficiency (i.e., age-related differences are more subtle in picture description tasks than in tasks that do not involve pictorial stimuli; Bortfeld et al., 2001; Mackenzie, 2000). Indeed, speech eliciting tasks placing fewer constraints on the participant' speech (e.g., conversation), could allow more opportunity for off-topic speech than picture description tasks.

An additional explanation for our findings could reside in methodological factors associated with the efficiency measure. Both our study and Cooper's (1990) scored for efficiency using a list of ICUs defined and validated prior to the investigation. In comparison, Capilouto et al. $(2005 ; 2016)$ found agerelated differences in speech efficiency using the percentage of correct information unit (CIU) method proposed by Nicholas and Brookshire (1993), while Le Dorze and Bédard (1998) and Mackenzie (2000) used a similar metric (i.e., the number of different content units per minute or words), and Kemper and Sumner (2001) measured the propositional density index. These studies accounted for all true and relevant information a posteriori, which suggests that means of evaluating the information content of discourse might impact the estimation of the participants' efficiency. For instance, measures such as ICUs/time and ICUs/words might not allow enough variability to detect age-related differences in speech efficiency. Thus, our method, though less timeconsuming and possibly more suitable for clinical settings, might be less sensitive to subtle variations in efficiency.

\section{Conclusion}

This study allowed the investigation of multiple aspects of speech production within a single sample, using a standardized and ecological task. In agreement with our expectations, we showed that normal aging didn't affect all aspects of language production equally. On the one hand, our results indicate an agerelated increase in the rate of disruptions to fluency, which could result from WFD, while lexical diversity, informativity, and efficiency of speech remain unaffected by age in our healthy, highly educated older group. On the other hand, the use of less frequent words by older adults could reflect an increase in vocabulary size with aging. Interaction effects found between picture stimulus and age suggest that the lexical frequency measure is sensitive to the stimulus' properties. Thus, we recommend that the choice of picture stimulus is taken into account if a study aims to estimate vocabulary size. For the other, possibly more clinically relevant connected speech measures that were investigated, the impact of age on speech production does not vary as a function of the stimulus used.

Knowledge of the way age-related changes appear in connected speech is needed to distinguish changes that are expected to occur with age alone from signs of neurodegenerative disorders. For instance, while it is well established that patients with $\mathrm{AD}$ experience more lexical retrieval difficulties than their healthy counterparts (Kavé \& Goral, 2016b), some studies suggested that a slight decline in naming abilities is one of the first predictors of conversion to $\mathrm{AD}$ (Mickes et al., 2007; Pekkala et al., 2013). However, these findings could not be systematically replicated across studies relying on confrontation naming (Schmidtke \& Hermeneit, 2008; Testa et al., 2004) and fluency tasks (Schmidtke \& Hermeneit, 2008). While such changes might be too subtle to allow consistent detection in standardized tasks involving single-word production at a preclinical stage, this study suggests that some measures of connected speech may be more sensitive to age-related changes in language production and could eventually prove useful in identifying changes in word-retrieval that could help predict conversion towards AD.

\section{References}

Ahmed, S., Haigh, A.-M. F., de Jager, C. A., \& Garrard, P. (2013). Connected speech as a marker of disease progression in autopsy-proven Alzheimer's disease. Brain, 136, 3727-3737. doi: 10.1093/brain/awt269

Arbuckle, T. Y., Nohara-LeClair, M., \& Pushkar, D. (2000). Effect of off-target verbosity on communication efficiency in a referential communication task. Psychology and Aging, 15, 6577. doi: 10. 1037/0882-7974.15.1.65 
Army Individual Test Battery. (1944). Manual of Directions and Scoring. Washington, DC: War Department Adjutant General's Office.

Bortfeld, H., Leon, S. D., Bloom, J. E., Schober, M. F., \& Brennan, S. E. (2001). Disfluency rates in conversation: Effects of age, relationship, topic, role, and gender. Language and Speech, 44, 123-147. doi: 10.1177/00238309010440020101

Brédart, S. (1993). Retrieval failures in face naming. Memory, 1, 351-366. doi: 10.1080/0965821930825 8243

Brickman, A. M., Paul, R. H., Cohen, R. A., Williams, L. M., MacGregor, K. L., Jefferson, A. L., . . . Gordon, E. (2005). Category and letter verbal fluency across the adult lifespan: relationship to EEG theta power. Archives of Clinical Neuropsychology, 20, 561-573. doi: 10.1016/j.acn.2004.12.006

Brookshire, R. H. \& Nicholas, L. E. (1994a). Speech sample size and test-retest stability of connected speech measures for adults with aphasia. Journal of Speech, Language, and Hearing Research, 37, 399407.

Brookshire, R. H. \& Nicholas, L. E. (1994b). Test-retest stability of measures of connected speech in aphasia. Clinical Aphasiology, 22, 119-133. doi: 10.1044/ jshr.3702.399

Bryant, L., Ferguson, A., \& Spencer, E. (2016). Linguistic analysis of discourse in aphasia: A review of the literature. Clinical Linguistics \& Phonetics, 30, 489-518. doi: 10.3109/02699206.2016.1145740

Burke, D. M., MacKay, D. G., \& James, L. E. (2000). Theoretical approaches to language and aging. In T. J. Perfect \& E. A. Maylor (Eds.), Debates in psychology. Models of cognitive aging (pp. 204-237). New York, NY: Oxford University Press.

Burke, D. M., Mackay, D. G., Worthley, J. S., \& Wade, E. (1991). On the tip of the tongue: What causes word finding failures in young and old adults? Journal of Memomy and Language, 30, 542-579. doi: 10.1016/0749-596X(91)90026-G

Burke, D. M. \& Shafto, M. A. (2004). Aging and language production. Current Directions in Psychological Science, 13, 21-24. doi: 10.1111/j.0963 -7214.2004.01301006.x

Capilouto, G., Wright, H. H., \& McComas Maddy, K. (2016). Microlinguistic processes that contribute to the ability to relay main events: influence of age. Aging, Neuropsychology, and Cognition, 23, 445463. doi: 10.1080/13825585.2015.1118006

Capilouto, G., Wright, H. H., \& Wagovich, S. A. (2005). CIU and main event analyses of the structured discourse of older and younger adults. Journal of Communications Disorders, 38, 431-444. doi: 10.1016/j.jcomdis.2005.03.005

Chapleau, M., Wilson, M. A., Potvin, K., HarveyLangton, A., Montembeault, M., \& Brambati, S. M. (2017). Word reading aloud skills: their positive redefinition through ageing. Journal of Research in Reading, 40, 297-312.

Chenery, H. J. \& Murdoch, B. E. (1994). The production of narrative discourse in response to animations in persons with dementia of the Alzheimer's type: Preliminary findings. Aphasiology, 8, 159-171. doi: 10.1080/02687039408248648

Clark, L. J., Gatz, M., Zheng, L., Chen, Y.-L., McCleary, C., \& Mack, W. J. (2009). Longitudinal verbal fluency in normal aging, preclinical and prevalent Alzheimer disease. American Journal of Alzheimer's Disease and Other Dementias, 24, 461-468. doi: 10.1177/1533317509345154

Colombo, F. T. \& Assal, G. (1992). Adaptation française $\mathrm{du}$ test de dénomination de Boston. Versions abrégées. Revue Européenne de Psychologie Appliquée, 42, 67-71.

Condret-Santi, V., Barbeau, E., Matharan, F., Le Goff, M., Dartigues, J.-F., \& Amieva, H. (2013). Prevalence of word retrieval complaint and prediction of dementia in a population-based study of elderly subjects. Dementia and Geriatric Cognitive Disorders, 35, 313-324.

Connor, L. T., Spiro, A., Obler, L. K., \& Albert, M. L. (2004). Change in object naming ability during adulthood. The Journals of Gerontology Series B: Psychological Sciences and Social Sciences, 59, 203209. doi: 10.1093/geronb/59.5.P203

Conroy, P., Sage, K., \& Ralph, M. L. (2011). Improved vocabulary production after naming therapy in aphasia: can gains in picture naming generalise to connected speech? International Journal of Language and Communication Disorders, 44, 1036-1062. doi: 10.1080/13682820802585975

Cooper, P. V. (1990). Discourse production and normal aging: Performance on oral picture description tasks. Journal of Gerontology, 45, 210-214. doi: 10.1093/ geronj/45.5.P210

Croisile, B., Ska, B., Brabant, M. J., Duchene, A., Lepage, Y., Aimard, G., \& Trillet, M. (1996). Comparative study of oral and written picture description in patients with Alzheimer's disease. Brain and language, 53, 1-19. doi: 10.1006/ brln.1996.0033

Dennis, P. A. \& Hess, T. M. (2016). Aging-related gains and losses associated with word production in connected speech. Neuropsychology, Development and Cognition., 23, 638-650. doi: 10.1080/13825585. 2016.1158233

Fergadiotis, G., Wright, H. H., \& Capilouto, G. J. (2011). Productive vocabulary across discourse types. Aphasiology, 25, 1261-1278. doi: 10.10 80/02687038.2011.606974

Fergadiotis, G., Wright, H. H., \& Green, S. B. (2015). Psychometric evaluation of lexical diversity indices: Assessing length effects. Journal of Speech, 
Language, and Hearing Research, 58, 840-852. doi: 10.1044/2015 JSLHR-L-14-0280

Field, A. (2013). Discovering statistics using IBM SPSS statistics (4th ed.). Thousand Oaks, CA: Sage Publications Ltd.

Fraser, K. C., Meltzer, J. A., Graham, N. L., Leonard, C., Hirst, G., Black, S. E., \& Rochon, E. (2014). Automated classification of primary progressive aphasia subtypes from narrative speech transcripts. Cortex, 55, 43-60. doi: 10.1016/j.cortex.2012.12.006

Glosser, G. \& Deser, T. (1992). A comparison of changes in macrolinguistic and microlinguistic aspects of discourse production in normal aging. Journal of Gerontology, 47, 266-272. doi: 10.1093/ geronj/47.4.P266

Goodglass, H., \& Kaplan, E. (1972). The assessment of aphasia and related disorders. Philadelphia, PA: Lea $\&$ Febiger.

Gordon, J. K. (2008). Measuring the lexical semantics of picture description in aphasia. Aphasiology, 22, 839852. doi: 10.1080/02687030701820063

Heine, M. K., Ober, B. A., \& Shenaut, G. K. (1999). Naturally occurring and experimentally induced tip-of -the-tongue experiences in three adult age groups. Psychology and Aging, 14, 445-457.

Howard, D. \& Patterson, K. (1992). The Pyramids and Palm Trees Test: A test of semantic access from words and pictures. Bury St Edmunds, Angleterre: Thames Valley Test Company.

Hughes, H. G. A. (2009). Dictionary of Linguistics and Phonetics (6th edition). Reference Reviews, 23, 33-34. doi: 10.1108/09504120910969041

James, L. E., Burke, D. M., Austin, A., \& Hulme, E. (1998). Production and perception of "verbosity" in younger and older adults. Psychology and Aging, 13, 355-367. doi: 10.1037/0882-7974.13.3.355

Jarvis, S. (2002). Short texts, best fitting curves and new measures of lexical diversity. Language Testing, 19, 57-84. doi: 10.1191/02655322021t220oa

Jensen, A. M., Chenery, H. J., \& Copland, D. A. (2006). A comparison of picture description abilities in individuals with vascular subcortical lesions and Huntington's disease. Journal of Communication Disorders, 39, 62-77. doi: 10.1016/j.jcom dis.2005.07.001

Joanette, Y., Nespoulous, J.-L., \& Roch Lecours, A. (1998). MT 86- Protocole Montréal-Toulouse d'examen linguistique de l'apahasie. Isbergues, France: Ortho Edition

Kavé, G. \& Goral, M. (2016a). Do age-related word retrieval difficulties appear (or disappear) in connected speech? Aging, Neuropsychology, and Cognition, 24, 508-527. doi: 10.1080/1382558 5.2016.1226249

Kavé, G. \& Goral, M. (2016b). Word retrieval in picture descriptions produced by individuals with Alzheimer's disease. Journal of Clinical and
Experimental Neuropsychology, 38, 958-966. doi: 10.1080/13803395.2016.1179266

Kavé, G., Samuel-Enoch, K., \& Adiv, S. (2009). The association between age and the frequency of nouns selected for production. Psychology and Aging, 24, 17 -27. doi: $10.1037 / \mathrm{a} 0014579$

Kavé, G. \& Yafé, R. (2014). Performance of younger and older adults on tests of word knowledge and word retrieval: Independence or interdependence of skills? American Journal of Speech-Language Pathology, 23, 36-45.

Kemper, S., Kynette, D., Rash, S., O'Brien, K., \& Sprott, R. (2008). Life-span changes to adults' language: Effects of memory and genre. Applied Psycholinguistics, 10, 49-66. doi: 10.1017/ S0142716400008419

Kemper, S. \& Sumner, A. (2001). The structure of verbal abilities in young and older adults. Psychology and Aging, 16, 312-322. doi: 10.1037/0882-7974.16.2.312

Kemper, S., Thompson, M., \& Marquis, J. (2001). Longitudinal change in language production: Effects of aging and dementia on grammatical complexity and propositional content. Psychology and Aging, 16, 600-614. doi: 10.1037//0882-7974.16.4.600

Larfeuil, C. \& Le Dorze, G. (1997). An analysis of the word-finding difficulties and of the content of the content of the discourse of recent and chronic aphasic speakers. Aphasiology, 11, 783-811. doi: 10.1080/02687039708250456

Le Dorze, G. \& Bédard, C. (1998). Effects of age and education on the lexico-semantic content of connected speech in adults. Journal of Communication Disorders, 31, 53-71. doi: 10.1016/ S0021-9924(97)00051-8

Light, L. L. \& Anderson, P. A. (1983). Memory for scripts in young and older adults. Memory \& Cognition, 11, 435-444. doi: 10.3758/BF03196980

Mackenzie, C. (2000). Adult spoken discourse: the influences of age and education. International Journal of Language \& Communication Disorders, 35, 269-285. doi: 10.1080/136828200247188

Mackenzie, C., Brady, M., Norrie, J., \& Poedjianto, N. (2007). Picture description in neurologically normal adults: Concepts and topic coherence. Aphasiology, 21, 340-354. doi:10.1080/ 02687030600911419

MacWhinney, B. (2000). The CHILDES Project: Tools for Analyzing Talk ( $3^{\text {rd }}$ ed). Mahwah, NJ: Lawrence Erlbaum Associate

MacWhinney, B. \& Wagner, J. (2010). Transcribing, searching and data sharing: The CLAN software and the TalkBank data repository. Gesprachsforschung: Online-Zeitschrift zur verbalen Interaktion, 11, 154-173.

Marini, A. Boewe, A., Caltagirone, C., \& Carlomagno, S. (2005). Age-related differences in the production of textual descriptions. Journal of Psycholinguist 
Research, 34, 439-463. doi: 10.1007/s10936-0056203-z

Mayer, J. \& Murray, L. (2003). Functional measures of naming in aphasia: Word retrieval in confrontation naming versus connected speech. Aphasiology, 17, 481-497. doi: 10.1080/02687030344000148

McKee, G., Malvern, D., \& Richards, B. (2000). Measuring vocabulary diversity using dedicated software. Digital Scholarship in the Humanities, 15, 323-338. doi: 10.1093/1lc/15.3.323

Mickes, L., Wixted, J. T., Fennema-Notestine, C., Galasko, D., Bondi, M. W., Thal, L. J., \& Salmon, D. P. (2007). Progressive impairment on neuropsychological tasks in a longitudinal study of preclinical Alzheimer's disease. Neuropsychology, 21, 696-705. doi: 10.1037/0894-4105.21.6.696

Montembeault, M., Brambati, S., Joubert, S., Boukadi, M., Chapleau, M., Laforce, R. J., . . . Rouleau, I. (2017). Naming unique entities in the semantic variant of primary progressive aphasia and Alzheimer's disease: Towards a better understanding of the semantic impairment. Neuropsychologia, 95, 11-20. doi: 10.1016/ j.neuropsychologia.2016.12.009

Mortensen, L., Meyer, A. S., \& Humphreys, G. W. (2006). Age-related effects on speech production: A review. Language and Cognitive Processes, 21, 238-290. doi: 10.1080/01690960444000278

Nasreddine, Z. S., Phillips, N. A., Bédirian, V., Charbonneau, S., Whitehead, V., Collin, I., . . . \& Chertkow, H. (2005). The Montreal Cognitive Assessment, MoCA: a brief screening tool for mild cognitive impairment. Journal of the American Geriatrics Society, 53, 695-699. doi: 10.1111/ j.1532-5415.2005.53221.x

New, B., Pallier, C., Ferrand, L., \& Matos, R. (2001) Une base de données lexicales du français contemporain sur internet: LEXIQUETM. L'Année Psychologique, 101, 447-462.

Nicholas, L. E. \& Brookshire, R. H. (1993). A system for scoring main concepts in the discourse of nonbrain-damaged and aphasic speakers. Clinical Aphasiology, 21, 87-99.

Nilsson, L. G. (2003). Memory function in normal aging. Acta Neurologica Scandinavica, 107, 7-13.

Owen Van Horne, A. \& Leonard, L. (2002). Lexical diversity in the spontaneous speech of children with specific language impairment. Journal of Speech, Language, and Hearing Research, 45, 927 937. doi: 10.1044/1092-4388(2002/075)

Pekkala, S., Wiener, D., Himali, J. J., Beiser, A. S., Obler, L. K., Liu, Y., . . . Wolf, P. A. (2013). Lexical retrieval in discourse: An early indicator of Alzheimer's dementia. Clinical Linguistics \& Phonetics, 27, 905-921. doi: 10.3109/0269 9206.2013 .815278
Risser, A. H. \& Spreen, O. (1985). The western aphasia battery. Journal of Clinical and Experimental Neuropsychology, 7, 463-470. doi: 10.1080/ 01688638508401277

Sajjadi, S. A., Patterson, K., Tomek, M., \& Nestor, P. J. (2012). Abnormalities of connected speech in semantic dementia vs Alzheimer's disease. Aphasiology, 26, 847-866. doi: 10.1080/02687038. 2012.654933

Salthouse, T. A. (2003). Interrelations of aging, knowledge, and cognitive performance. In U. M. Staudinger \& U. Lindnberger (Eds.), Understanding human development (pp. 265-287). Heidelberg, Allemagne: Springer.

Salthouse, T. A., Toth, J., Daniels, K., Parks, C., Pak, R., Wolbrette, M., \& Hocking, K. J. (2000). Effects of aging on efficiency of task switching in a variant of the trail making test. Neuropsychology, 14, 102111.

Schmidtke, K. \& Hermeneit, S. (2008). High rate of conversion to Alzheimer's disease in a cohort of amnestic MCI patients. International Psychogeriatrics, 20, 96-108. doi: 10.1017/ S1041610207005509

Schmitter-Edgecombe, M., Vesneski, M., \& Jones, D. W. R. (2000). Aging and word-Finding: A comparison of spontaneous and constrained naming tests. Archives of Clinical Neuropsychology, 15, 479-493. doi: 10.1016/S0887-6177(99)00039-6

Shewan, C. M. \& Henderson, V. L. (1988). Analysis of spontaneous language in the older normal population. Journal of Communication Disorders, 21, 139-154. doi: 10.1016/0021-9924(88)90002-0

Slegers, A., Filiou, R.-P., Montembeault, M., \& Brambati, S. M. (2018). Connected speech features from picture description in Alzheimer's disease: A systematic review. Journal of Alzheimer's Disease, 65, 519-542. doi: 10.3233/JAD-170881

Spieler, D. H. \& Griffin, Z. M. (2006). The influence of age on the time course of word preparation in multiword utterances. Language and Cognitive Processes, 21, 291-321. doi: 10.1080/ 01690960400002133

Testa, J. A., Ivnik, R. J., Boeve, B., Petersen, R. C., Pankratz, V. S., Knopman, D., . . . Smith, G. E. (2004). Confrontation naming does not add incremental diagnostic utility in MCI and Alzheimer's disease. Journal of the International Neuropsychological Society, 10, 504-512. doi: 10.1017/S1355617704104177

Thornton, R. \& Light, L. L. (2006). Language comprehension and production in normal aging. In J. E. Birren, K. W. Schaie, R. P. Abeles, M. Gatz, \& T. A. Salthouse (Eds.), Handbook of the Psychology of Aging (pp. 261-287). Cambridge, MA: Elsevier.

Tombaugh, T. N., Kozak, J., \& Rees, L. (1999). Normative data stratified by age and education for 
two measures of verbal fluency: FAS and animal naming. Archives of Clinical Neuropsychology, 14, 167-177. doi: 10.1093/arclin/14.2.167

Vandenborre, D., Visch-Brink, E., van Dun, K., Verhoeven, J., \& Mariën, P. (2018). Oral and written picture description in individuals with aphasia. International Journal of Language \& Communication Disorders, 53, 294-307. doi: 10.1111/14606984.12348

Verhaegen, P. (2003). Aging and vocabulary score: A meta-analysis. Psychology and Aging, 18, 332-339. doi: 10.1037/0882-7974.18.2.332

Verhaegen, C., \& Poncelet, M. (2012). Changes in naming and semantic abilities with aging from 50 to 90 years. Journal of the International Neuropsychological Society, 19, 119-126. doi: 10.1017/S1355617712001178

Wechsler, D. (2008). Wechsler adult intelligence scaleFourth Edition (WAIS-IV). San Antonio, TX: NCS Pearson.

Wright, H. H., Capilouto, G. J., Srinivasan, C., \& Fergadiotis, G. (2011). Story processing ability in cognitively healthy younger and older adults. Journal of Speech, Language, and Hearing Research : JSLHR, 54, 900-917. doi: 10.1044/1092-4388 (2010/09-0253)

Received January 7, 2019

Revision received March 26, 2019

Accepted July 14, 2019 